\title{
CONTACT ANALYSIS OF CHAIN DRIVE IN SCRAPER CONVEYOR BASED ON DYNAMIC MESHING PROPERTIES
}

\author{
Jiang, S. B. ; Zeng, Q. L. .,\#; Wang, G. ; Gao, K. D. ; Wang, Q. Y.* \& Hidenori, K.** \\ ${ }^{*}$ College of Mechanical and Electronic Engineering, Shandong University of Science and Technology, \\ Qingdao 266590, China \\ *** PSC Co., Ltd., Kanagawa-ken, 225-0013, Japan \\ E-Mail: qlzeng@sdust.edu.cn (\# Corresponding author)
}

\begin{abstract}
The chain drive system is the most important subsystem in a mining scraper conveyor. Compared with the general chain drive system, that in a scraper conveyor is highly coupled. The rings on a chain come in contact not only with the sprocket wheels but also with the central chutes and scrapers. In order to improve the reliability of the scraper conveyor, a contact analysis of the chain drive system based on its meshing properties was performed. Vogit model-based translational and rotating models of the chain drive system were first introduced. A finite element model of the chain drive system was then established. Contact simulations were conducted using the software LS-DYNA. Von Mises stress and contact pressure curves on various dangerous areas of the horizontal ring, vertical ring, and sprocket wheel were obtained. The von Mises stress and the contact pressure of the rings and the sprocket wheel were compared, and their differences were analysed. Results indicate that the maximum contact pressure for the horizontal and vertical rings is considerably larger than the maximum von Mises stress. The maximum contact pressure for the horizontal ring exceeds $2000 \mathrm{MPa}$, which is $90 \%$ larger than the von Mises stress (1100 MPa). Meanwhile, the contact pressure for the sprocket wheel is considerably less than the von Mises stress. Therefore, the failure mode of the rings and the sprocket wheels differs. Contact analysis based on meshing properties is useful in describing the dynamic properties of the chain drive system in detail. This study provides guidance for overcoming chain break and jam problems in scraper conveyors.

(Received in July 2017, accepted in December 2017. This paper was with the authors 1 month for 1 revision.)
\end{abstract}

Key Words: Scraper Conveyor, Contact Analysis, Dynamic Properties, Chain Drive

\section{INTRODUCTION}

The scraper conveyor is the only coal transportation equipment in long wall mining faces [1]. The scraper conveyor, coal shearer, and hydraulic support comprise a modern fully mechanized coal mining equipment group [2, 3]. Under working conditions, the scraper conveyor not only transports coal but also works as the running track of the coal shearer and moving fulcrum of the hydraulic support. Therefore, the scraper conveyor is the core equipment in the fully mechanized coal mining equipment group. Hence, the reliability of this equipment plays a significant part.

The most important subsystem in a scraper conveyor is the chain drive system, which comprises one or two chains and at least two sprocket wheels. Chains and sprocket wheels then constitute a closed loop with the chains run around the sprocket wheels. The performance of the chain drive system can directly determine the reliability of the scraper conveyor. Chain drive systems often encounter such problems as chain break and jam in the working environment, and these problems are caused by many factors. First, coal flow cut by a shearer is inhomogeneous, thereby leading to an uneven load of the chain drive system in the scraper conveyor. The uneven load can then cause severe vibration in the chain drive system [4]. Second, the laying length of a scraper conveyor can reach hundreds of meters. A sudden increase in coal flow at one point on the conveyor can cause a chain jam problem [5-7]. Third, the chain drive system in a scraper conveyor is more complex than a general 
chain drive system. The rings on a chain in a scraper conveyor not only mesh with the sprocket wheel but are also fixed with scrapers. The rings and scrapers run along the central chute. This structure can cause contact problems and produce high resistance as the chain drive system transports coals. These factors lead to the requirement of scraper conveyors for high-performance chain drive systems. Therefore, the contact problem of chain drive systems in scraper conveyors based on meshing properties must be studied to improve the reliability of scraper conveyors.

\section{STATE OF THE ART}

Several scholars have studied the dynamic properties and attempted to improve the performance of chain drive systems in scraper conveyors. Chain tension is an important approach and can reflect the dynamic properties of the conveyor to a certain extent. Wang et al. [8] designed a dynamic tension test equipment to obtain the dynamic properties of the chain drive system in a scraper conveyor. Similarly, Dolipski et al. [9] introduced an adaptive adjustment system for the chain drive. Chain tensions were monitored in real time, and the drive frame automatically changed with the chain tensions. This method is efficient but requires that the detection devices be installed on the sprocket wheels and is thus not suitable for scraper conveyors in service, especially in mining environments, which demand harsh explosion-proof requirements. Swider et al. $[10,11]$ pointed out the unpredictability of loads on a scraper conveyor. They studied the relationship between chain tensions and loads indirectly by obtaining the frequency of driving motor voltage under horizontal or inclined conditions. This method cannot reflect the real dynamic properties of the chain drive system. Dolipski et al. $[12,13]$ created a physical and mathematical model that helped determine the dynamic loads of a chain drive system. The results of the computer simulations were useful. However, conducting a computer simulation was difficult for a complete scraper conveyor model with a laying length of up to $350 \mathrm{~m}$. The simulation process could consume too much time and hardware. Jiang et al. [14] established rigid and rigid-flexible coupling models of the chain drive system. Simulations under full-, half-, and empty-load conditions were performed, and the dynamic and vibration properties were obtained using the software ADAMS. The proposed rigid-flexible coupling model had certain limitations. Not all the rings in the simulation model were flexible. Therefore, not all the rings' stress and strain could be obtained.

In addition, several scholars investigated the dynamic properties from other aspects. The chain drive system in a scraper conveyor is highly coupled. Rings on a chain not only mesh with sprocket wheels but also run in the central chute. Therefore, research was conducted by certain scholars from the aspect of tribology. Shi and Zhu [15] studied middle plates' wear properties and mechanisms in detail. They constructed a practical statistical wear mechanism distribution diagram. Krawczyk and Pawlowski [16] determined the tribological properties of a scraper conveyor with two chains to improve the reliability of the chain drive system. The proposed method provides references for studying the contact properties of chain drive systems. Sobota [17] proposed a modified sprocket wheel, which could reduce friction in the front and rear joints, unlike traditional sprocket wheels. Mao et al. [18] established a new mathematical model to calculate the load spectrum of a scraper conveyor. By this model, the dynamic properties of a scraper conveyor were obtained and tension changes and real-time adjustment at any time and position of the scraper conveyor were achieved. Nie et al. [19, 20] introduced a new method of predicting and evaluating the dynamic properties of the chain drive system in a scraper conveyor under different working conditions. They used the Karnopp model and developed simulation codes through MATLAB/Simulink. Simulation results were useful in protecting the chain drive system. 
The abovementioned studies attempted to describe the dynamic properties of the chain drive system from various viewpoints but still had certain limitations. The experiment based on chain tension monitoring is efficient, but installing monitoring devices on a scraper conveyor, especially that in service, is difficult. Meanwhile, a chain tension test based on motor loads is an indirect method that cannot directly reflect the dynamic properties of the chain drive system. Computer simulations based on numerical analyses have been widely used in engineering [21]. Thus, a contact analysis of a chain drive system based on its meshing properties is performed in this study to accurately describe its dynamic behaviour.

The remainder of this study is organized as follows. Section 3 introduces the translational and rotating models of the chain drive system. On the basis of these models, a finite element model of the chain drive system is established and a contact analysis of the chain drive system is performed. Section 4 compares the von Mises stresses and contact pressures of the horizontal ring, vertical ring, and sprocket wheel. The dynamic behaviours of the chain drive system are discussed in detail from the contact analysis perspective. Section 5 summarizes the conclusions.

\section{METHODOLOGY}

\subsection{Chain drive modelling in scraper conveyor}

The chain drive models are established in Solidworks software. The models are then imported to the software LS-DYNA. To study the contact properties between the chains and the sprocket wheel without reducing simulation efficiency, hexahedral mesh is used to construct the finite element model, because hexahedral element is efficient for structural analysis [22]. The stress and strain of the sprocket wheel are minimal, and many elements that can reduce the simulation efficiency will occur after meshing. Thus, the chain drive system is simplified as a system containing a rigid wheel with 7 flexible teeth, 11 flexible horizontal rings, and 11 vertical rings, as shown in Fig. 1.

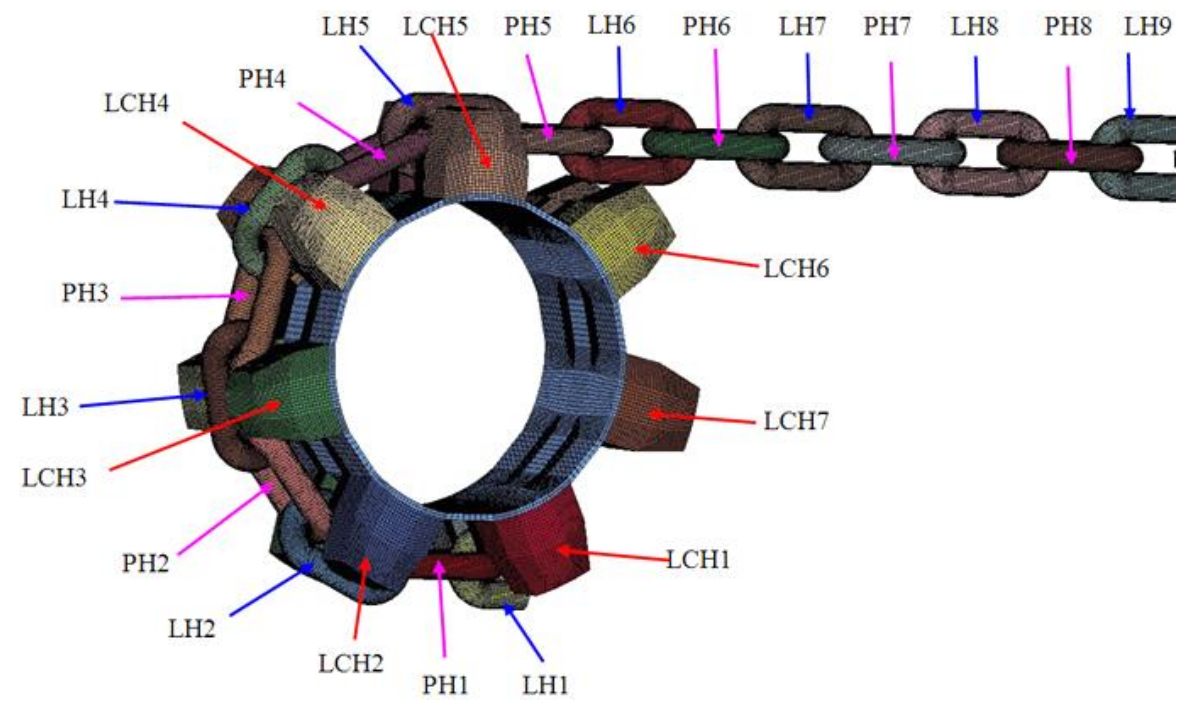

Figure 1: Finite element model of the chain drive system.

The 7 flexible teeth are named LCH1-LCH7, and the 11 horizontal rings and 11 vertical rings are named PH1-PH11 and LH1-PH11, respectively. At least three integral meshing periods can be guaranteed, thereby contributing to the simulation effects. The sprocket wheel is meshed with the rigid inner ring and flexible teeth because the moment load cannot be applied on a deformed element in the finite element software. The rigid and flexible areas are jointed through public boundary nodes. The moment load is applied on the rigid area and can 
then be transferred to the flexible teeth. The finite element models of the chain drive are illustrated in Fig. 2. The models contain 807,300 elements and 896,038 nodes.

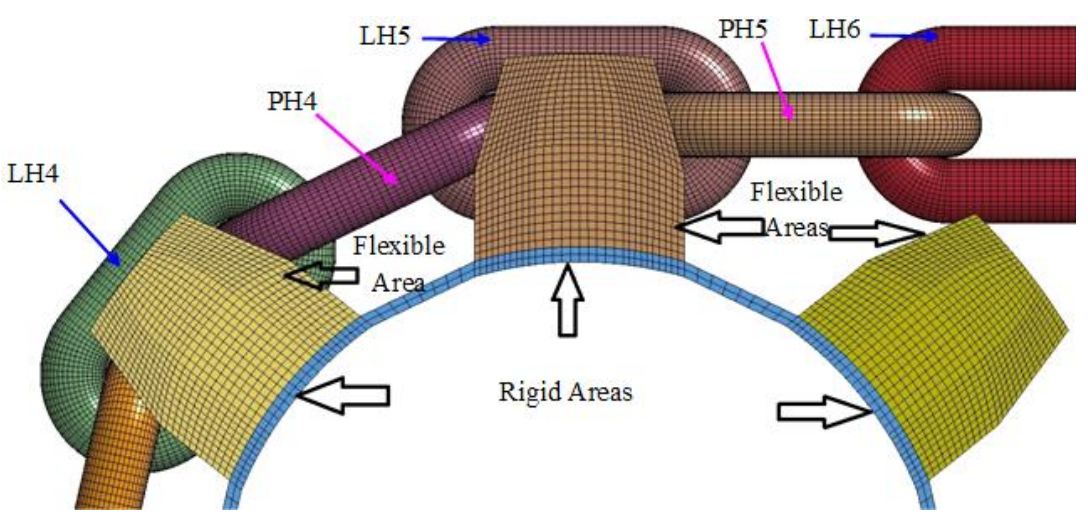

Figure 2: Rigid-flexible coupling model of the chain drive system.

\subsection{Translational model of the chain drive system}

Theoretical analyses and experiments have proven that the Vogit model is more accurate than other models in describing the contact status by regarding the chain as a viscoelastic material. As shown in Fig. 3, a Vogit model is constituted in parallel by a spring and a damper. In Fig. $3, k$ is the stiffness coefficient, $c$ is the viscous damping coefficient, $x$ is the displacement, and $F$ is the force. During elongation, the spring is influenced by the damper, and the damper's elongation also affects the secondary elongation of the spring. Therefore, this model meets the properties of rings in the chain drive system, as shown in Fig. 4.

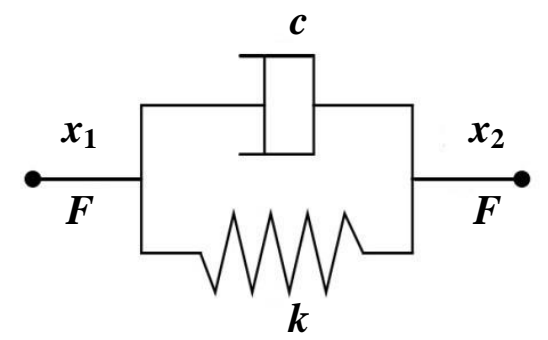

Figure 3: Vogit model of a translational ring.

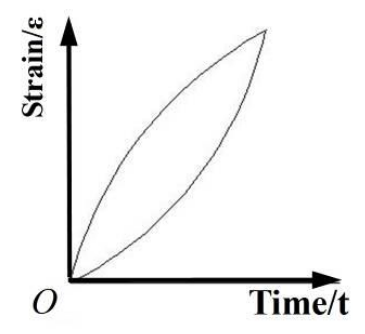

Figure 4: Strain curve of the Vogit model.

The Vogit model of a ring in the chain drive system can be expressed as follows:

$$
F=k\left(x_{2}-x_{1}\right)+c\left(\dot{x}_{2}-\dot{x}_{1}\right)
$$

where, $k$ is stiffness coefficient, which is related to the structural, material, and force parameters; $c$ is the viscous damping coefficient, which can be determined by experiments; $x$ is the displacement; and $\dot{x}$ is the velocity.

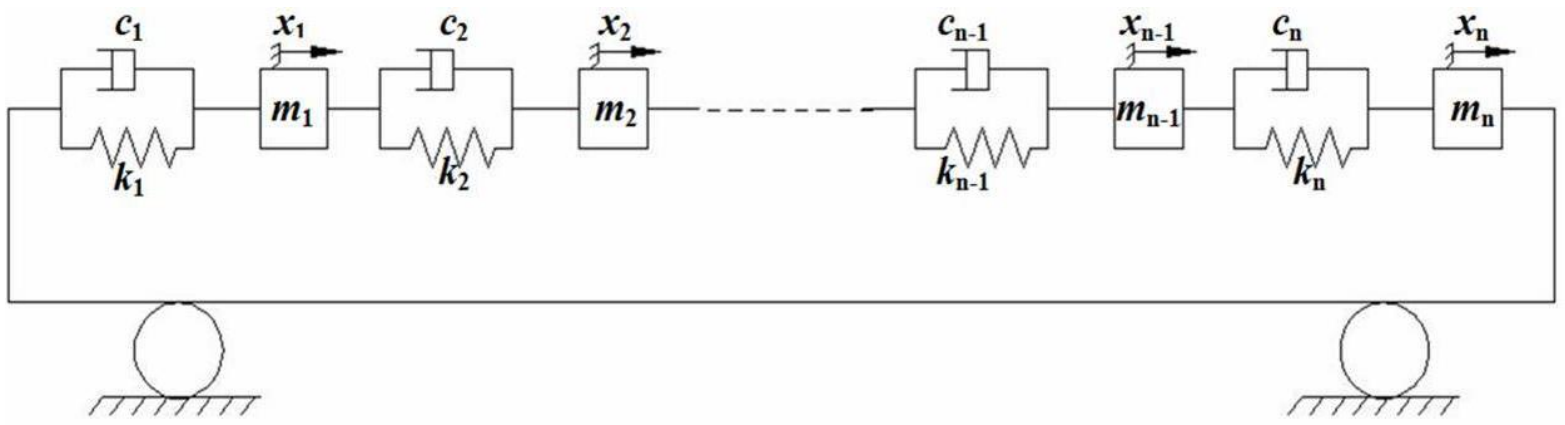

Figure 5: Vogit model of the chain drive system in a scraper conveyor. 
In analysing the properties of the chain drive system, its translational model can be approximately seen as a closed-loop model with $n$ Vogit models because the whole chain consists of $n$ rings, as shown in Fig. 5; $c_{i}$ is the damping coefficient of the $i^{\text {th }}$ ring, $k_{i}$ is the stiffness coefficient of the $i^{\text {th }}$ ring, and $m_{i}$ stands for the mass of the $i^{\text {th }}$ ring.

Therefore, the kinetic equation of the $i^{\text {th }}$ ring is expressed as follows:

$$
m \ddot{x}+c_{i}\left(\dot{x}_{i}-\dot{x}_{i-1}\right)+c_{i+1}\left(\dot{x}_{i}-\dot{x}_{i-1}\right)+k_{i}\left(x_{i}-x_{i-1}\right)+k_{i+1}\left(x_{i}-x_{i+1}\right)=f_{i}(t)
$$

where, $x_{i}$ stands for the displacement of the $i^{\text {th }}$ ring, for $i=1,2, \ldots, n$.

\subsection{Rotating model of the chain drive system}

When the rings rotate around the sprocket wheel, relative rotation exists between rings and relative sliding occurs between contact areas. Therefore, the dynamics contact model of the rings includes not only the spring and the damper but also friction, as shown in Fig. 6, where $k$ is the stiffness coefficient, $c$ is the viscous damping coefficient, $x$ is the displacement, $F$ is the force, and $F_{f 1}$ is the friction. The equation of the dynamics model can be expressed as follows:

$$
F=k x_{r}+c \frac{d x_{r}}{d t}+F_{f 1}
$$

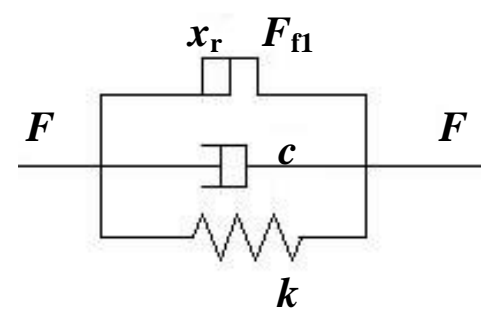

Figure 6: Vogit model of a rotating ring.

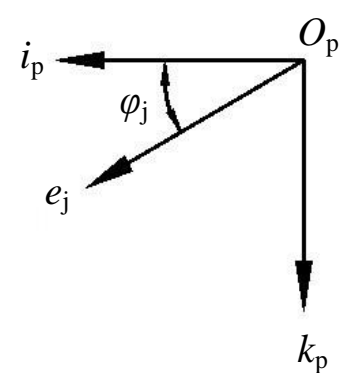

Figure 7: Rotating angle of a horizontal ring.

As shown in Fig. 7, when the $j^{\text {th }}$ horizontal ring rotates around the sprocket wheel by angle $\varphi_{j}$, the central line of the horizontal ring is along the direction of $e_{j}$. If force $F$, damping coefficient $c$, stiffness coefficient $k$, and friction $F_{f 1}$ are decomposed along the horizontal and vertical directions, their components can be expressed as follows:

$$
\left\{\begin{array}{cc}
F_{i p}=F \cos \varphi_{j} & F_{k p}=F \sin \varphi_{j} \\
x_{i p}=x_{r} \cos \varphi_{j} & x_{k p}=x_{r} \sin \varphi_{j} \\
F_{f 1-i p}=F_{f 1} \cos \varphi_{j} & F_{f 1-k p}=F_{f 1} \sin \varphi_{j}
\end{array}\right.
$$

where, $F_{i p}, x_{i p}$, and $F_{f 1-i p}$ are the components of force, displacement, and friction, respectively, of the $j^{\text {th }}$ horizontal ring along horizontal direction; $F_{k p}, x_{k p}$, and $F_{f 1-i p}$ are the same components along vertical direction.

Therefore, the kinetic equation of the $j^{\text {th }}$ horizontal ring at angle $\varphi_{j}$ is expressed as follows:

$$
\begin{aligned}
& F_{i p}=k x_{r} \cos \varphi_{j}-c \sin \varphi_{j} \frac{d x_{r}}{d t}+F_{f 1} \cos \varphi_{j} \\
& F_{k p}=k x_{r} \sin \varphi_{j}-c \cos \varphi_{j} \frac{d x_{r}}{d t}+F_{f 1} \sin \varphi_{j}
\end{aligned}
$$

\subsection{Definitions of material properties and boundaries}

According to the product manual of the type SGZ1000/1400 scraper conveyor, the materials of the ring and the sprocket wheel's material are 23MnNiCrMo and 30CrMnTi respectively. 
Table I shows the parameters of the two materials.

Table I: Material parameters of the rings and sprocket wheel.

\begin{tabular}{|c|c|c|c|c|c|}
\hline Item & $\begin{array}{c}\text { Density } \\
\left(\mathrm{kg} / \mathrm{mm}^{3}\right)\end{array}$ & $\begin{array}{c}\text { Elastic modulus } \\
(\mathrm{GPa})\end{array}$ & $\begin{array}{c}\text { Poisson's } \\
\text { ratio }\end{array}$ & $\begin{array}{c}\text { Shear modulus } \\
(\mathrm{GPa})\end{array}$ & $\begin{array}{c}\text { Yield limit } \\
(\mathrm{GPa})\end{array}$ \\
\hline Rings & $7.86 \times 10^{-6}$ & 210 & 0.25 & $5.6 \times 10^{-4}$ & $1.167 \times 10^{-3}$ \\
\hline Wheel & $7.85 \times 10^{-6}$ & 210 & 0.29 & $5.6 \times 10^{-4}$ & $1.6 \times 10^{-3}$ \\
\hline
\end{tabular}

In LS-DYNA software, settings of simulation parameters are achieved and edited via KEYWORD.

(1) Load

Load is applied by applying force on the end nodes of the rings. Two end faces of vertical ring \#1 (LH1) and horizontal ring \#11 (PH11) are given 482 nodes, and these faces are set as two components. Tensions of sprocket and chain, which are obtained by the software ADAMS [14], are applied on these two components to perform a simulation under full working conditions.

(2) Driving rotating speed

The driving rotation speed is achieved by defining the time field curve on the rigid wheel. The 7 teeth established can provide sufficient meshing periods. Thus, we set the rotating speed of the wheel as a constant $3.95 \mathrm{rad} / \mathrm{s}$ after $0.1 \mathrm{~s}$.

\section{RESULT ANALYSIS AND DISCUSSION}

We set the simulation time as $1.2 \mathrm{~s}$, each step lasts $0.01 \mathrm{~s}$. The solver in LS-DYNA has no limits for CPU cores, and the result of each step is automatically exported as a d3plot file; consequently, the chain drive simulation is efficiently performed on a workstation for $5 \mathrm{~h}$. The distributions of stress and strain, energy changes, displacement, and velocity of elements and nodes can be obtained from the simulation result. For the chain drive system, the von Mises stresses and the contact pressures of the rotating horizontal ring, rotating vertical ring, and the sprocket wheel nest must be studied.

\subsection{Rotating horizontal ring}

Fig. 8 shows the stress distribution of a rotating horizontal ring. A horizontal ring contacts the wheel nest and the nearby vertical ring. Therefore, stress concentrations mainly occur on the three areas (a, b, and c), as shown in Fig. 8. The dynamic behaviours in the three areas of the horizontal ring are to be discussed in detail.

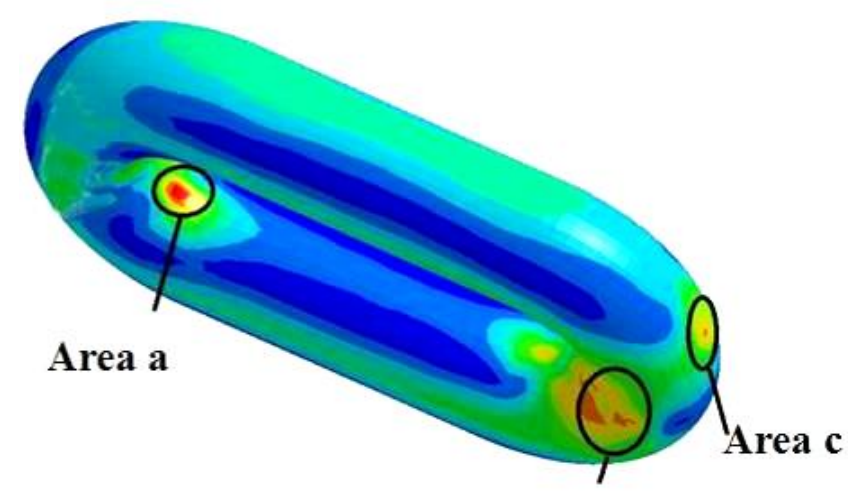

Area b

Figure 8: Stress distribution of horizontal ring \#5 (PH5). 
According to the initial settings, the horizontal ring starts to accelerate at $0-0.1 \mathrm{~s}$. Horizontal ring \#5 contacts only the nearby vertical rings and does not mesh with the wheel nest. Therefore, the horizontal ring bears tensions only from the nearby vertical rings, and the von Mises equivalent stresses mainly occur on the curve and cylinder sections. The maximum von Mises stress on the stress concentrations is over $1000 \mathrm{MPa}$, which exceeds the yield limit, and plastic deformation occurs. At 0.1-1.2 s, the wheel rotates at a constant rotation speed. During this period, areas a-c on horizontal ring \#5 successively contact the wheel nest. Von Mises stresses in areas $\mathrm{b}$ and $\mathrm{c}$ reach the yield limit. As the horizontal ring rotates around the wheel, stress concentration occurs on the joint area between the curve and cylinder sections. This phenomenon happens because the moment and rotating speed of the wheel are transferred into the tension and velocity of the ring as the horizontal ring rotates around the wheel.

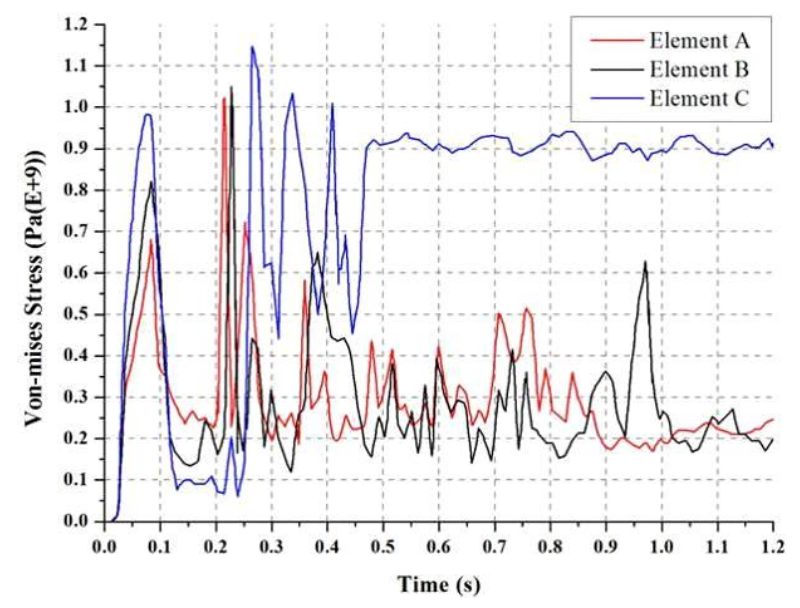

Figure 9: Von Mises stress curves of elements A, $\mathrm{B}$, and $\mathrm{C}$ on horizontal ring \#5 (PH5).

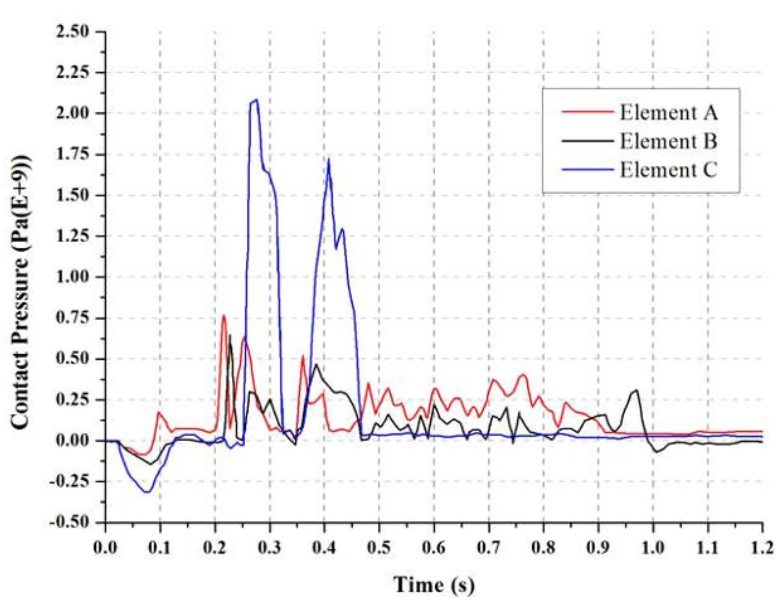

Figure 10: Contact pressure curves of elements A, $\mathrm{B}$, and $\mathrm{C}$ on horizontal ring \#5 (PH5).

To further investigate, we select three elements $\mathrm{A}, \mathrm{B}$, and $\mathrm{C}$ from areas $\mathrm{a}, \mathrm{b}$, and c, respectively, on horizontal ring \#5. These three elements are all from the stress concentration areas, and Fig. 9 shows the von Mises stress curves of the corresponding elements. At 0.2$0.45 \mathrm{~s}$, the stress curves vibrate violently and horizontal ring \#5 rotates by 1 tooth $(51.43$ degrees). Therefore, in this process, moment is transferred by the wheel to areas a, b, and c. At 0.82-1.0 s, horizontal ring \#5 separates from the wheel. The stress in element A decreases slightly, whereas that in element B initially increases and then decreases. This change in the stress in element B indicates that vibration still occurs between the wheel and horizontal ring $\# 5$, with focus on area $b$.

Contact pressures in the contact areas between the horizontal ring and the wheel occur successively according to the pressure curves of elements A, B and C, as shown in Fig. 10. Unlike that shown in Fig. 9, the maximum von Mises stress occurs at negative pressure at $0.05-0.1 \mathrm{~s}$. This finding indicates that the wheel is in the accelerating stage and the stress status of elements $\mathrm{A}, \mathrm{B}$, and $\mathrm{C}$ is in the stage of pulling. As the horizontal ring contacts the wheel, the negative pressure becomes positive. The maximum pressure in element $\mathrm{C}$ reaches $2098 \mathrm{MPa}$ with two apparent vibrations. The maximum pressure in element $\mathrm{B}$ is $653 \mathrm{MPa}$, and the trend of the pressure curve is similar to that of the von Mises stress curve. For element A, pressure is positive at $0.1-0.9 \mathrm{~s}$, and this finding is an indication of contact occurring in area a. Meanwhile, contact pressure is maintained at $300 \mathrm{MPa}$. The pressure curves of the elements also reflect that the energy transfer stage occurs as the horizontal ring rotates around the first tooth of the wheel. 


\subsection{Rotating vertical ring}

Fig. 11 shows the von Mises stress contour of vertical ring \#7 (LH7) as it rotates around the wheel at $0.408 \mathrm{~s}$. Areas a, b, and c represent the contact areas, which are also the stress concentration areas, between vertical ring \#7 and horizontal ring \#6.

Area b

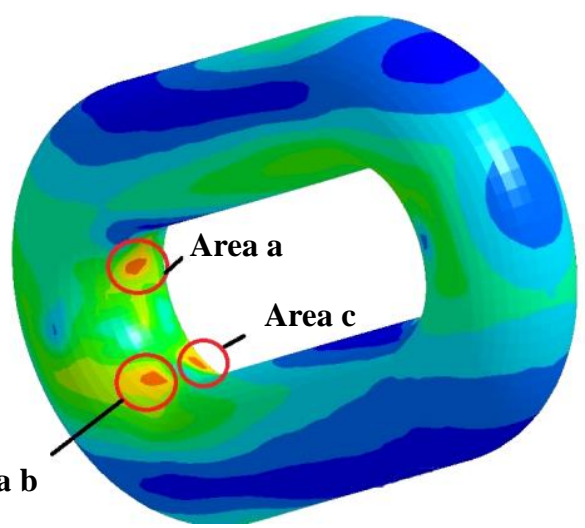

Figure 11: Stress distribution of vertical ring \#7 (LH7).

As the vertical ring rotates around the wheel, a relative rotation also occurs between the vertical and horizontal rings. Areas $b$ and $c$ distribute symmetrically by the axis of the vertical ring. We select three elements $\mathrm{A}, \mathrm{B}$, and $\mathrm{C}$ from areas $\mathrm{a}, \mathrm{b}$, and c, respectively. The von Mises stress and pressure curves of the elements from 0 to $1.2 \mathrm{~s}$ are shown in Figs. 12 and 13, respectively.

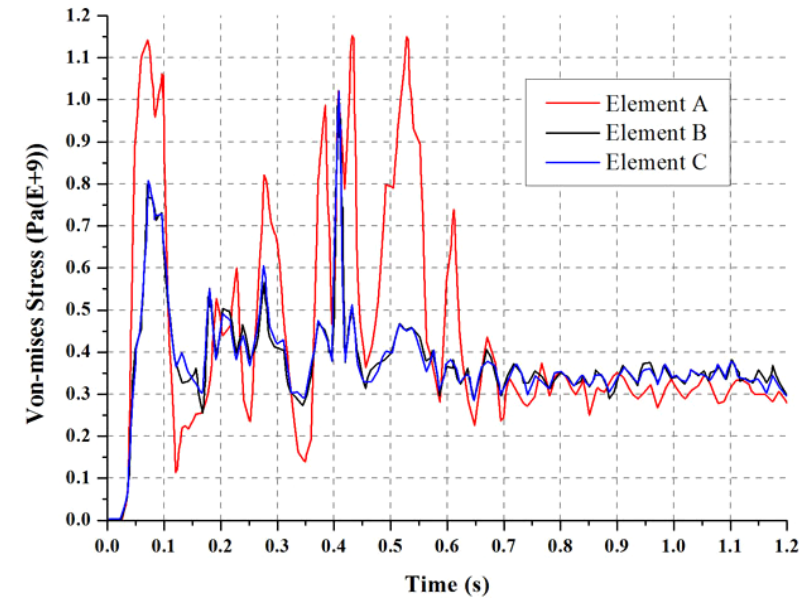

Figure 12: Von Mises stress curves of elements A, $\mathrm{B}$, and $\mathrm{C}$ on vertical ring \#7 (LH7).

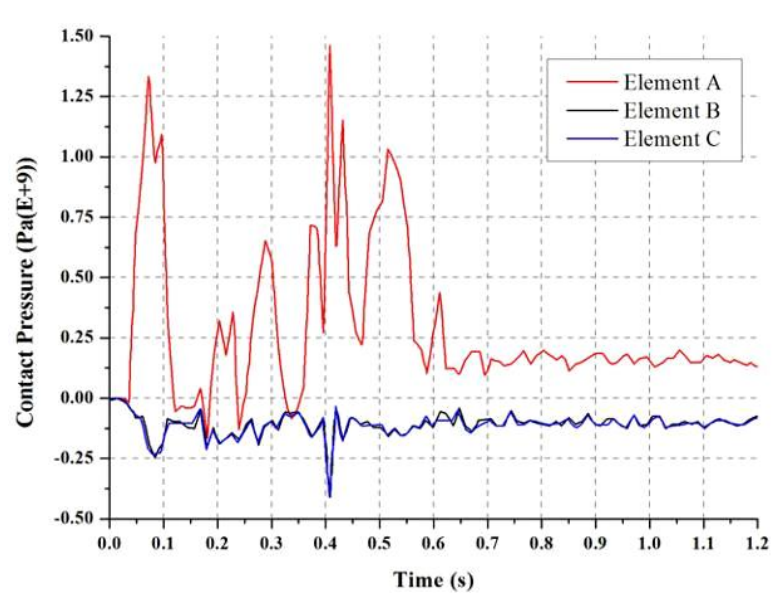

Figure 13: Contact pressure curves of elements $\mathrm{A}, \mathrm{B}$, and $\mathrm{C}$ on vertical ring \#7 (LH7).

According to Figs. 12 and 13, the maximum stress of over $1150 \mathrm{MPa}$ occurs in element A. The first crest is at $0.06 \mathrm{~s}$, which is when the wheel starts to accelerate. At $0.36 \mathrm{~s}$, the second stress crest occurs and the movement of horizontal ring \#6 changes from horizontal to rotational. At $0.36 \mathrm{~s}$, fluctuations occur in the von Mises stress and contact pressure curves. After $0.6 \mathrm{~s}$, vertical ring \#7 completely meshes with the wheel. Before separation with the wheel, no relative rotation occurs between horizontal ring \#6 and vertical ring \#7. Therefore, stress and pressure maintain stability after $0.6 \mathrm{~s}$.

\subsection{Sprocket wheel}

Fig. 14 shows the von Mises stress contour of the sprocket wheel at $0.264 \mathrm{~s}$. When the wheel contacts the horizontal ring, stress concentration mainly occurs in areas a, b, and c, as Fig. 14 
illustrates. Moreover, stress concentrations are more apparent in areas a and c than those in area $b$. These findings match the actual situation.

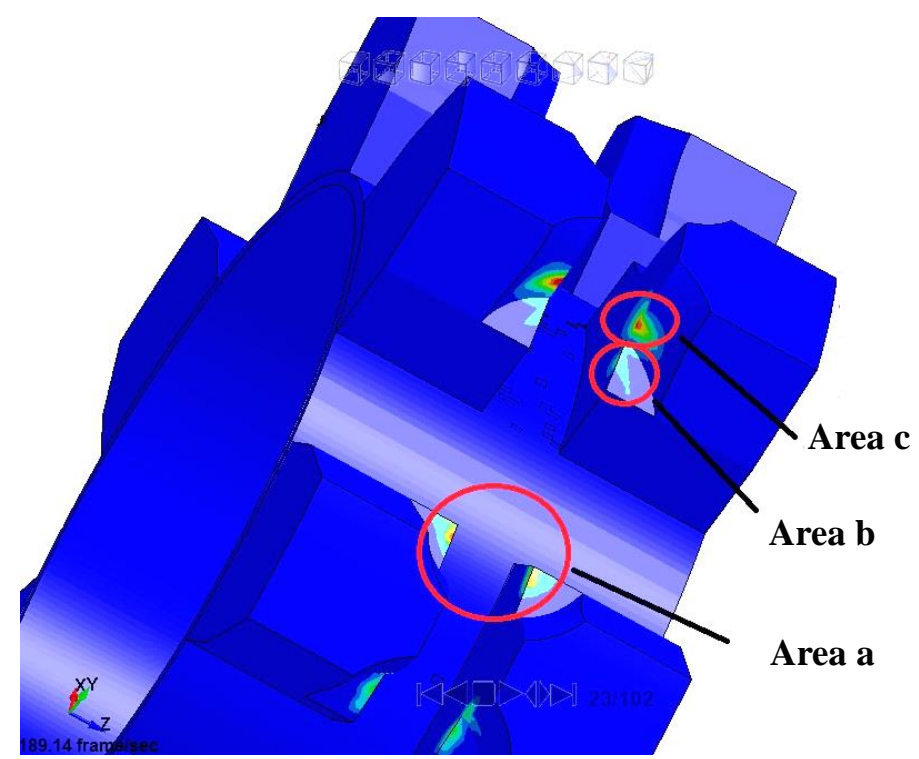

Figure 14: Stress distribution of the sprocket wheel.

Three elements A, B, and C are selected from areas a, b, and c, respectively. The von Mises stress and contact pressure curves are illustrated in Figs. 15 and 16, respectively. The von Mises stress of element $A$ is the maximum with a value of $1636 \mathrm{MPa}$ and then settles at $1400 \mathrm{MPa}$. For element A, the stable contact pressure is $1700 \mathrm{MPa}$, which is larger than the von Mises stress. For elements B and C, the trends of the stress and contact pressure curves are similar.

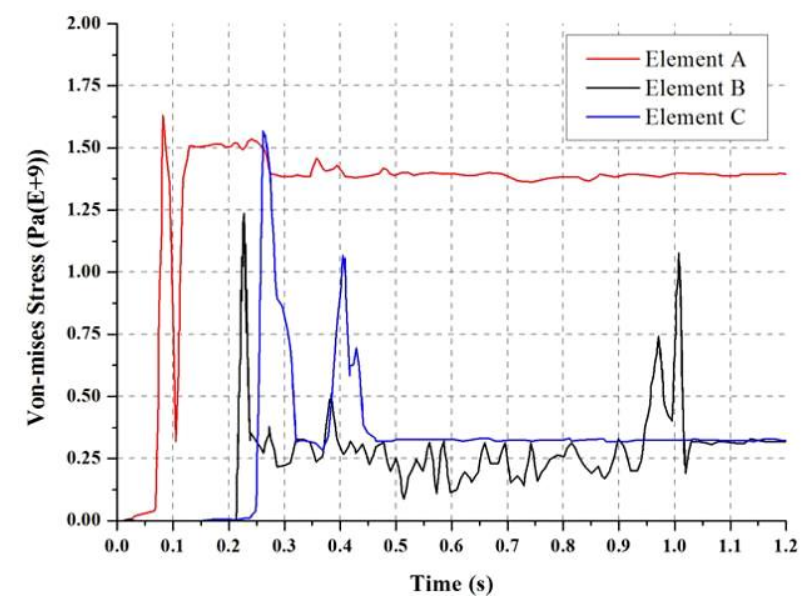

Figure 15: Von Mises stress curves of elements A, $\mathrm{B}$, and $\mathrm{C}$ on the sprocket wheel.

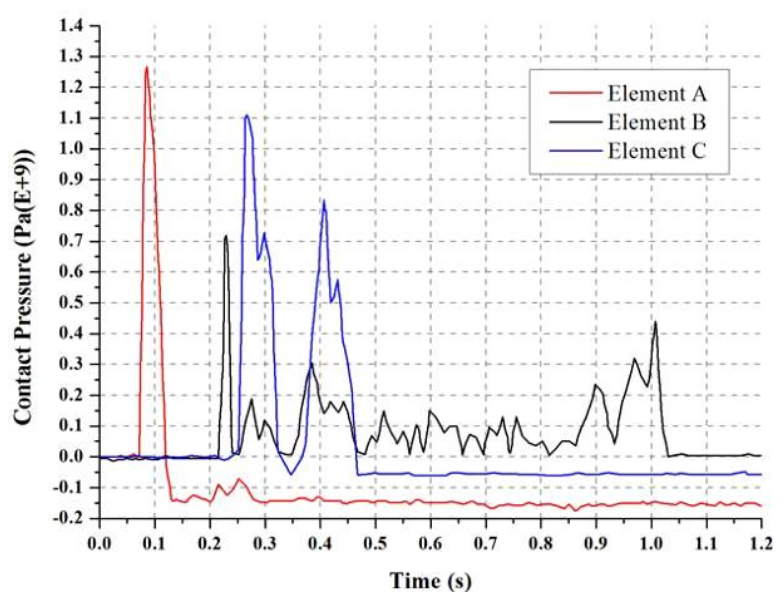

Figure 16: Contact pressure curves of elements $\mathrm{A}, \mathrm{B}$, and $\mathrm{C}$ on the sprocket wheel.

\section{CONCLUSION}

To overcome chain break and jam problems in scraper conveyors, a finite element model of the chain drive system was established. This model was based on translational and rotating models. A contact analysis of the chain drive system based on its meshing properties was performed. The von Mises stress and contact pressure curves of the horizontal ring, the vertical ring, and sprocket wheel were obtained and compared. Conclusions are drawn as follows. 
(1) As the wheel starts to rotate, the maximum von Mises stress of the dangerous areas on a horizontal ring that meshes with the sprocket wheel is over $1100 \mathrm{MPa}$ and the maximum contact pressure is over $2000 \mathrm{MPa}$. The contact pressure attributes to the chain break during this stage.

(2) In a vertical ring, the contact pressure of area a differs considerably from that of the two other areas because the movement of the vertical ring changes from translation into rotation. Therefore, the material performance of areas $\mathrm{b}$ and $\mathrm{c}$ in a vertical ring should be improved to prevent chain break.

(3) Unlike the maximum von Mises stresses of the horizontal and vertical rings, that of the sprocket wheel is larger than the maximum contact pressure. This finding indicates that the sprocket wheel's failure mode is different with chains.

The chain drive system in a scraper conveyor is highly coupled, and studying the chain drive system's dynamic properties from the aspect of contact analysis is an essential approach. This study provides guidance and is useful in overcoming the problems of chain break and jam in engineering. However, in the chain drive system, contact problem exists not only between rings and sprocket wheel but also between rings and scrapers, between rings and central chutes, and between scrapers and central chutes. Therefore, contact analyses for these areas should be considered to obtain accurate results.

\section{ACKNOWLEDGEMENT}

This work was supported by the National Natural Science Fund of China (Grant No. 51674155), Innovative Team Development Project of Ministry of Education (Grant No. IRT_16R45), Natural Science Foundation of Shandong Province (Grant No. ZR2016EEM09), Postdoctoral Innovation Foundation Funded Project of Shandong Province (Grant No. 201603057) and Postdoctoral Applied Research Project of Qingdao City (Grant No. 2016120).

\section{REFERENCES}

[1] Hao, S. Q.; Wang, S. B.; Malekian, R.; Zhang. B. Y.; Liu, W. L.; Li, Z. X. (2017). A geometry surveying model and instrument of a scraper conveyor in unmanned longwall mining faces, IEEE Access, Vol. 5, 4095-4103, doi:10.1109/ACCESS.2017.2681201

[2] Xie, J. C.; Yang, Z. J.; Wang, X. W.; Wang, S. P.; Zhang, Q. (2017). A joint positioning and attitude solving method for shearer and scraper conveyor under complex conditions, Mathematical Problems in Engineering, Vol. 2017, Paper ID 3793412, 14 pages, doi:10.1155/2017/3793412

[3] Lu, E.; Li, W.; Yang, X. F.; Xu, S. Y. (2017). Composite sliding mode control of a permanent magnet direct-driven system for a mining scraper conveyor, IEEE Access, Vol. 5, 22399-22408, doi:10.1109/ACCESS.2017.2761846

[4] Stoicuta, O.; Pana, T.; Mandrescu, C. (2016). The control system analysis of the coal flow on the scrapers conveyor in a longwall mining system, 2016 International Conference on Applied and Theoretical Electricity (ICATE), 10 pages, doi:10.1109/ICATE.2016.7754614

[5] Ordin, A. A.; Metel'kov, A. A. (2015). Analysis of longwall face output in screw-type cutterloader-and-scraper conveyor system in underground mining of flat-lying coal beds, Journal of Mining Science, Vol. 51, No. 6, 1173-1179, doi:10.1134/S1062739115060452

[6] Wang, A. M.; Cheng, X. H.; Meng, G. Y.; Wo, L.; Pang, Z. D. (2016). Experimental study on the welding procedure of the central groove of armored face conveyor, Advances in Mechanical Engineering, Vol. 8, No. 10, 1-12, doi:10.1177/1687814016674101

[7] Stecula, K.; Brodny, J. (2016). Application of the OEE model to analyze the availability of the mining armored face conveyor, $16^{\text {th }}$ International Multidisciplinary Scientific Geoconference (SGEM 2016), 57-64 
[8] Wang, H. J.; Zhang, Q.; Xie, F. (2017). Dynamic tension test and intelligent coordinated control system of a heavy scraper conveyor, IET Science Measurement \& Technology, Vol. 11, No. 7, 871-877, doi:10.1049/iet-smt.2016.0425

[9] Dolipski, M.; Cheluszka, P.; Remiorz, E.; Sobota, P. (2015). Follow-up chain tension in an armoured face conveyor, Archives of Mining Sciences, Vol. 60, No. 1, 25-38, doi:10.1515/amsc2015-0002

[10] Swider, J.; Herbus, K.; Szewerda, K. (2017). Dynamic analysis of scraper conveyor operation with external loads, The $4^{\text {th }}$ International Conference on Computing and Solutions in Manufacturing Engineering (CoSME), Paper 01009, 6 pages, doi:10.1051/matecconf/ 20179401009

[11] Szewerda, K.; Swider, J.; Herbus, K. (2017). Analysis of impact of longitudinal inclination of a chain conveyor on dynamical phenomena during operation, The $4^{\text {th }}$ International Conference on Computing and Solutions in Manufacturing Engineering (CoSME), Paper 01010, 7 pages, doi:10.1051/matecconf/20179401010

[12] Dolipski, M.; Remiorz, E.; Sobota, P. (2012). Determination of dynamic loads of sprocket drum teeth and seats by means of a mathematical model of the longwall conveyor, Archives of Mining Sciences, Vol. 57, No. 4, 1101-1119, doi:10.2478/v10267-012-0073-7

[13] Dolipski, M.; Remiorz, E.; Sobota, P. (2014). Dynamics of non-uniformity loads of AFC drives, Archives of Mining Sciences, Vol. 59, No. 1, 155-168, doi:10.2478/amsc-2014-0011

[14] Jiang, S. B.; Zhang, X.; Gao, K. D.; Gao, J.; Wang, Q. J.; Hidenori, K. (2017). Multi-body dynamics and vibration analysis of chain assembly in armoured face conveyor, International Journal of Simulation Modelling, Vol. 16, No. 3, 458-470, doi:10.2507/IJSIMM16(3)8.391

[15] Shi, Z. Y.; Zhu, Z. C. (2017). Case study: Wear analysis of the middle plate of a heavy-load scraper conveyor chute under a range of operating conditions, Wear, Vol. 380-381, 36-41, doi:10.1016/j.wear.2017.03.005

[16] Krawczyk, J.; Pawlowski, B. (2013). The analysis of the tribological properties of the armoured face conveyor chain race, Archives of Mining Sciences, Vol. 58, No. 4, 1251-1262, doi: 10.2478/amsc-2013-0086

[17] Sobota, P. (2016). Comparison of conventional sprocket drum and sprocket drum with modified design, Archives of Mining Sciences, Vol. 61, No. 3, 509-522, doi:10.1515/amsc-2016-0037

[18] Mao, J.; Xie, C. X.; Liu, Z. X.; Xie, M. (2017). A new method for simulating load spectrum of scraper conveyor and developing its simulation system, Mechanical Science and Technology for Aerospace Engineering, Vol. 36, No. 10, 1512-1520, doi:10.13433/j.cnki.1003-8728.2017.1006

[19] Nie, R.; He, B. Y.; Zhang, L. H.; Li, G. P. (2014). Modelling of the transmission system in conveying equipment based on Euler method with application, Proceedings of the Institution of Mechanical Engineers, Part K: Journal of Multi-Body Dynamics, Vol. 228, No. 3, 294-306, doi:10.1177/1464419314534787

[20] Nie, R.; He, B. Y.; Yuan, P. F.; Zhang, L. H.; Li, G. P. (2015). Novel approach to and implementation of design and analysis of armored face conveyor power train, Science China Technological Sciences, Vol. 58, No. 12, 2153-2168, doi:10.1007/s11431-015-5895-Z

[21] Wang, Z.; Huang, X.; Zhou, J. P. (2013). A numerical method for delayed fractional-order differential equations: based on G-L definition, Applied Mathematics \& Information Sciences, Vol. 7, No. 2, 525-529, doi:10.12785/amis/072L22

[22] Rivera, M. G.; Reddy, J. N. (2017). Nonlinear transient and thermal analysis of functionally graded shells using a seven-parameter shell finite element, Journal of Modeling in Mechanics and Materials, Vol. 1, No. 2, Paper 20170003, doi:10.1515/jmmm-2017-0003 